ESPAÇO TEMÁTICO: VIOL ÊNCIA, SAÚDE E CLASSES SOCIAIS

\title{
Violência de gênero entre usuárias do serviço de atenção básica do SUS na Paraíba
}

\author{
Idalina Maria Freitas Lima Santiago ${ }^{1}$ \\ https://orcid.org/0000-0002-4752-0260 \\ ${ }^{1}$ Universidade Estadual da Paraíba, Departamento de Serviço Social, Programa de Pós-Graduação em Serviço Social, \\ Campina Grande, PB, Brasil
}

\begin{abstract}
Violência de gênero entre usuárias do serviço de atenção básica do SUS na Paraíba
Resumo: Este artigo problematiza a violência de gênero vivenciada pelas usuárias das Unidades de Saúde da Família (USF), do Sistema Único de Saúde (SUS), e o atendimento prestado por este serviço no combate de tais violências. Busca apontar os marcadores sociais das usuárias que passaram por violência de gênero; tipificar as violências de gênero vivenciadas por essas mulheres; identificar os procedimentos tomados por elas para enfrentar essas violências; analisar o atendimento das USF no combate à violência de gênero. Trata-se de pesquisa analítico-descritiva e abordagem quanti-qualitativa, envolvendo as cidades de João Pessoa, Campina Grande, Cajazeiras e Patos, na Paraíba. A amostra é constituída por 600 usuárias e 21 profissionais de saúde. As USF investigadas não se constituem espaços de interlocução com as mulheres violentadas, não efetivando o referenciamento para a Rede de Atendimento.
\end{abstract}

Palavras-chave: Violência contra a mulher. Política Pública de Saúde. Rede de Atendimento.

\section{Gender violence among users of the SUS primary care service in Paraíba}

Abstract: This paper discusses the gender violence experienced by users of the Family Health Units (USF), of the Unified Health System (SUS), and the assistance provided by this service in combating such violence. It seeks to point out the social markers of users who have experienced gender violence; typify the gender violence experienced by these women; identify the procedures taken by them to face these violence; to analyze USF assistance in combating gender violence. This is an analytical-descriptive research with a quantitative and qualitative approach, involving the cities of João Pessoa, Campina Grande, Cajazeiras and Patos, in Paraíba. The sample consists of 600 users and 21 health professionals. The USF investigated do not constitute spaces for dialogue with the abused women and do not refer to the Service Network.

Keywords: Violence against women. Public Health Policy. Service Network.

Recebido em 12.11.2020. Aprovado em 15.12.2020. Revisado em 25.02.2021.

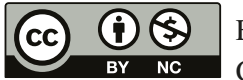

Este é um artigo publicado em acesso aberto (Open Access) sob a licença Creative Commons Attribution NonCommercial, que permite uso, distribuição e reprodução em qualquer meio, sem restrições desde que sem fins comerciais e que o trabalho original seja corretamente citado. 


\section{Introdução}

A violência doméstica e familiar ${ }^{1}$ contra a mulher no Brasil se constitui em uma questão premente a ser priorizada pela gestão pública, se levarmos em consideração as significativas taxas de aumento de homicídios de mulheres nos últimos anos. Quando comparados os resultados das pesquisas desenvolvidas em 2010 e 2013, registradas no Mapa da Violência 2015 de Homicídios de Mulheres no Brasil, percebemos que, em 2013, houve aumento de 9\% em relação ao número de assassinatos de mulheres registrados em 2010 (MAPA..., 2015).

Gustafson (2019), em matéria publicada no portal Catarinas, informa que, em 2019, o Brasil caminhava para liderar o ranking mundial de violência contra a mulher, apresentando a informação da organização internacional Human Rights Watch, segundo a qual a taxa de homicídios no Brasil é maior do que em qualquer outro país componente da Organização para a Cooperação e Desenvolvimento Econômico (OECD).

Em relação ao estado paraibano, segundo o Anuário da Segurança Pública da Paraíba, os casos de assassinatos de mulheres, de 2009 a 2018, oscilaram bastante, tendo a maior taxa ocorrida em 2011, com 164 mortes. Em 2018, houve um declínio nessa taxa, contabilizando-se 84 mulheres vítimas de crimes letais e intencionais (FECHINE, 2019). Contudo, há tendência de crescimento desse índice para o ano de 2020, pois no primeiro semestre já foram registradas, pela Secretaria de Segurança e Defesa Social, 46 mortes de mulheres por crimes letais intencionais (PB..., 2020).

O Brasil possui uma das legislações mais avançadas para coibir a violência contra a mulher, envolvendo uma série de pactos e acordos entre os entes federativos, sendo a Lei Maria da Penha, $\mathrm{n}^{\circ} 11.340 / 2006$, e a Lei de Feminicídio, n 13.104/2015 (BRASIL, 2015), marcos exponenciais na prevenção e criação de mecanismos para coibir tal violência. Contudo, falta celeridade na implantação e aplicação dessas legislações. Conforme prevê a Lei Maria da Penha, no seu Art. 09, três políticas públicas constituem o pilar para o enfrentamento dessa violência:

A assistência à mulher em situação de violência doméstica e familiar será prestada de forma articulada e conforme os princípios e as diretrizes previstos na Lei Orgânica da Assistência Social, no Sistema Único de Saúde, no Sistema Único de Segurança Pública, entre outras normas e políticas públicas de proteção e emergenciamento quando for o caso (BRASIL, 2006, p. 21).

A reflexão em torno da violência doméstica e familiar no campo da saúde está ancorada em algumas normativas, das quais destacamos a Política Nacional de Atenção Integral à Saúde da Mulher (BRASIL, 2004), que prevê ações nos níveis de atenção básica, média e alta complexidade; a Lei nº 12.845/2013, que dispõe sobre o atendimento obrigatório e integral de pessoas em situação de violência sexual (BRASIL, 2013); e a Lei $n^{\circ} 10.778 / 2003$, que estabelece a notificação compulsória, no território nacional, dos casos de violência contra as mulheres atendidas em serviços de saúde públicos ou privados (BRASIL, 2003).

As Unidades de Saúde da Família (USF) fazem parte da Estratégia Saúde da Família, a qual se constitui em estratégia prioritária para a reorganização da atenção básica à saúde, sendo a porta de entrada do/a usuário/a no Sistema Único de Saúde (SUS).

Tomando como base essas legislações, que demarcam o SUS como um dos atores prioritários no combate à violência doméstica e familiar, neste artigo problematizamos a questão da violência de gênero vivenciada pelas mulheres que acessam às USF e o atendimento prestado por este serviço no combate de tais violências. Para tanto, buscamos apresentar os marcadores socioeconômicos, geracionais, de orientação sexual e étnico-raciais das mulheres usuárias das USF que passaram por processos de violência doméstica e familiar; tipificar as violências vivenciadas por essas mulheres apontando seus agressores; identificar os procedimentos tomados pelas mulheres para os encaminhamentos direcionados ao combate dessas violências, ao tempo em que detectamos os serviços vinculados à Rede de Atendimento às Mulheres em Situação de Violência nos municípios pesquisados; e analisar o atendimento prestado pelas USF acerca do combate à violência de gênero.

A pesquisa teve como eixo metodológico à abordagem descritivo-analítica, a partir da coleta de dados quantitativos e qualitativos. A proposta envolveu dois tipos de pesquisa: uma de caráter documental, por meio de consulta a documentos e/ou relatórios das secretarias municipais, estadual e nacional de saúde; e outra que compreendeu a obtenção dos dados junto às usuárias das Unidades de Saúde da Família, gestoras responsáveis pela área técnica de saúde da mulher, ou sua correlata, e enfermeiras/os das USF nos municípios pesquisados. 
O campo de investigação foi definido tomando como referência a Resolução CIB/PB no 193/2012, de 04 de setembro de 2012, da Secretaria Estadual de Saúde, a qual referenciou as cidades de Cajazeiras, João Pessoa, Patos e Campina Grande como regiões prioritárias da Paraíba para implementação do Plano de Ação Regional da Rede de Atenção à Saúde no âmbito do SUS. Esse plano de ação destinou recursos e serviços para as cidades escolhidas, as quais se tornaram centros de referência para os municípios circunvizinhos (BRASIL, 2012).

João Pessoa, capital do Estado, situa-se na região da Mata correspondente à faixa de clima úmido que acompanha o litoral, sendo a parte mais povoada e mais urbanizada do Estado. Campina Grande, segunda maior cidade do Estado, encontra-se localizada na região do Agreste, a qual representa a transição entre a zona da Mata e a região do Sertão, destacando-se por ser um polo de produção tecnológica no país. Já as cidades de Patos e Cajazeiras estão fixadas na região do Sertão, que correspondente a uma área de vegetação da caatinga, constituindo o semiárido paraibano.

Para a escolha das unidades de saúde, utilizamos como base de dados a lista das USF dos municípios pesquisados, disponível no Cadastro Nacional de Estabelecimentos de Saúde e nos sites das prefeituras. Nessas listas, foi possível ter acesso à quantidade e localização das USF em cada cidade. Dessa forma, fixou-se $25 \%$ do total da quantidade de USF em cada cidade, tomando como critério a conveniência operacional da pesquisa.

Considerando que em Cajazeiras existiam 17 USF, em Patos 40, em Campina Grande 72 e em João Pessoa 127, por ocasião da coleta de dados (julho/2014 a abril/2015), a quantidade de unidades pesquisadas ficou assim estabelecida: cinco em Cajazeiras; dez em Patos; 18 em Campina Grande; e 32 em João Pessoa. Para a seleção das unidades pesquisadas, utilizamos uma amostragem simples através de uma função aleatória no Excel, tendo-se o cuidado de excluir as USF situadas nas zonas rurais dos municípios. Assim, o âmbito de abrangência deste estudo incluiu as áreas urbanas.

Além disso, considerando que eram atendidas mensalmente nas USF uma média de 16.434 famílias em Cajazeiras, 27.421 em Patos, 76.014 em Campina Grande e 161.632 em João Pessoa ${ }^{2}$ e supondo que cada família era composta por pelo menos 1 (uma) mulher, foi estabelecida uma amostra de 150 mulheres para cada cidade. Para saber se as amostras provinham de uma população infinita, utilizamos a fração amostral $\frac{\mathrm{n}}{\mathrm{N}}<0,05$ ( $\mathrm{n}=150$ e $\mathrm{N}=$ número de famílias atendidas pelas USF nos municípios) e, assim, obtivemos o erro amostral. Dessa forma, a partir da Tabela 1, foi possível constatar que cada fração amostral não ultrapassou 0,05 , referendando a pesquisa, já que a população de cada cidade foi infinita.

Assim, o erro amostral máximo atingido foi de 6,7\% em Cajazeiras, Patos, Campina Grande e em João Pessoa, levando em consideração o tamanho da amostra de 150 indivíduos no uso do cálculo amostral pela proporção "estimador $=$ p e (1-p)". Isto significa que sobre as variáveis dos quesitos de interesse o erro foi de, no máximo, $6,7 \%$ e a confiança estabelecida em $90 \%$. Na Tabela 2 demonstramos a quantidade de USF e de usuárias pesquisadas em cada cidade.

Tabela 1 - Fração de amostragem de interesse em cada cidade

\begin{tabular}{c|c|c|c}
\hline Cajazeiras & Patos & Campina Grande & João Pessoa \\
\hline$\frac{150}{16434}=0,009127$ & $\frac{150}{27421}=0,005470$ & $\frac{150}{76014}=0,001973$ & $\frac{150}{161632}=0,000928$ \\
\hline
\end{tabular}

Fonte: Dados da pesquisa.

Tabela 2 - Amostragem em cada cidade

\begin{tabular}{l|c|c|c|c}
\hline \multicolumn{1}{c|}{ Cidade } & Cajazeiras & Patos & Campina Grande & João Pessoa \\
\hline Unidades Saúde da Família & 05 & 10 & 18 & 32 \\
Usuárias pesquisadas & 150 & 150 & 150 & 150 \\
\hline
\end{tabular}

Fonte: Dados da pesquisa. 
Dessa amostra total de 600 mulheres pesquisadas, fazem parte do recorte analítico do presente artigo as usuárias que passaram por vivências de violência doméstica e familiar, contabilizando 32 em Cajazeiras (21,3\%), 25 em Patos (16,7\%), 29 em Campina Grande (19,3\%) e 56 em João Pessoa (37,3\%). Cabe destacar que, no ano de 2015, João Pessoa figurava como a terceira capital brasileira com maiores índices de violência contra a mulher, perdendo para Vitória/ES e Maceió/AL (MAPA..., 2015).

A coleta dos dados primários se deu através da aplicação de questionários junto às usuárias das USF, com idade superior a 18 anos, e entrevistas semiestruturadas, gravadas e transcritas, com as gestoras responsáveis pela área técnica de saúde da mulher ou de atenção básica, bem como enfermeiras/os das equipes de saúde. A coleta de dados ocorreu aleatoriamente entre as mulheres/usuárias que buscavam atendimento nas USF durante os dias de permanência da equipe de pesquisadoras/es nas citadas unidades.

Como o município de Patos possuía quatro distritos sanitários, chamados de distritos geoadministrativos, foram entrevistadas uma (1) enfermeira de USF de cada um desses quatro distritos e a gerente de Atenção Básica da Secretaria Municipal de Saúde, contabilizando cinco informantes. O município de Cajazeiras, por ser de menor porte, não possuía na estrutura administrativa da Secretaria de Saúde a divisão das áreas por distritos. Como a cidade estava distribuída geograficamente entre zona norte, sul e rural, os serviços de saúde foram agrupados a partir dessas zonas. Desse modo, as entrevistas foram realizadas com quatro enfermeiras/ os das USF, sendo duas da zona norte e duas da zonal sul, além da gerente de Saúde da Mulher da Criança e do Adolescente.

A Secretaria de Saúde de João Pessoa dividia suas áreas de atuação em cinco distritos sanitários. Dessa forma, as entrevistas foram realizadas com uma (1) enfermeira das USF de cada um desses distritos e a gestora de Saúde da Mulher da referida secretaria. Já a Secretaria de Saúde de Campina Grande contava com oito distritos sanitários, estabelecendo duas classificações para identificar as USF: porte I, equivalente a possuir uma equipe de saúde; e porte 2, por terem em sua estrutura mais de uma equipe de saúde. Para seleção das enfermeiras entrevistadas, tomamos como critério de escolha as USF de porte II, distribuídas entre os distritos, por agregarem maior número de usuários nos seus atendimentos. Assim, participaram das entrevistas quatro enfermeiras alocadas neste tipo de USF em distritos diferentes, além da gerente de Saúde da Mulher³.

Para garantir a legitimidade das informações coletadas, foi apresentado às usuárias, gestoras e enfermeiras/ os o Termo de Consentimento Livre e Esclarecido (TCLE) para referendar suas participações na pesquisa, após aprovação da mesma pelo Comitê de Ética da UEPB, com o protocolo 33787114.0.0000.5187.

O texto está estruturado em três subtópicos. O primeiro abordará os marcadores sociais das mulheres violentadas; o segundo tratará os aspectos da violência doméstica e familiar, bem como apontará os serviços vinculados à Rede de Atendimento às Mulheres em Situação de Violência; e o terceiro refletirá acerca do atendimento prestado pelas USF voltado para a violência de gênero.

\section{Marcadores sociais das mulheres violentadas}

O levantamento dos marcadores sociais das mulheres usuárias das USF que passaram por processos de violência de gênero permitiu analisarmos aspectos relevantes sobre a idade, autoidentificação da cor/raça e orientação sexual, estado civil, escolaridade, trabalho e renda. É oportuno destacar que $100 \%$ dessas mulheres se autoidentificaram com o marcador da cisgeneridade, havendo identificação entre sua condição de gênero e o sexo biológico determinado no nascimento. Dessa forma, não houve autoidentificação de pessoa transgênera.

A faixa etária prevalecente nas quatro cidades se concentrou na geração de pessoas adultas ( 30 a 60 anos), demarcada com 78,2\% em Cajazeiras, 60,0\% em Patos, 58,5\% em Campina Grande e 62,5\% em João Pessoa. Podemos perceber que os percentuais dessa faixa etária nas quatro cidades foram aproximados, não havendo uma diferença significativa. Também foi detectada representatividade na faixa etária juvenil de 18 a 29 anos, sendo a maior na cidade de Patos, com 36,0\%, e a menor na cidade de Cajazeiras, com 18,8\%. Campina Grande e João Pessoa apresentaram percentuais aproximados, sendo $31,0 \%$ e $28,6 \%$, respectivamente. O recorte geracional com menor representatividade foi o das idosas, com menor índice nas cidades de Cajazeiras $(3,1 \%)$ e Patos (4,0\%), seguidos de João Pessoa (8,9\%) e Campina Grande (10,3\%). Dessa forma, essa amostragem evidencia que as usuárias das USF que vivenciaram processos de violência nas quatro ${ }^{4}$ cidades encontravam-se em idade reprodutiva, que, segundo o Ministério da Saúde, compreende de 10 aos 49 anos de idade. 
Em relação à autoidentificação relacionada ao quesito cor/raça, iniciamos a pesquisa utilizando as cinco categorias de pertencimento racial que foram encontradas por Osório (2003) nos censos do IBGE: branco, pardo, negro, amarelo e indígena. Contudo, no decorrer do processo investigativo, houve grande incidência da denominação "morena" como uma categoria de pertencimento racial, a qual passou a constar como indicador na pesquisa. Sendo assim, foi possível perceber que 66,6\% das mulheres violentadas de João Pessoa, 65,6\% de Cajazeiras, 58,6\% em Campina Grande e 56\% de Patos indicaram designações relacionadas à condição de afrodescendência, no caso negra, parda e morena, com prevalência das nomeações parda e morena. $\mathrm{O}$ índice de autodeclaração como branca apareceu em segundo lugar, não tendo havido identificação como indígena, isso nas quatro cidades.

Quanto ao estado civil, a maioria das mulheres violentadas encontrava-se numa relação estável, sendo 59,4\% em Cajazeiras, 58,9\% em João Pessoa, 48,3\% Campina Grande e 48\% em Patos. Em segundo lugar, nos percentuais das quatro cidades, a condição de solteira teve maior destaque, seguida da situação de separada ou divorciada. Cabe registrar que, comparativamente ao universo total da pesquisa com as 600 usuárias, os índices de separadas ou divorciadas no recorte de mulheres violentadas foi significativamente maior, o que pode indicar o rompimento dos laços conjugais em decorrência das situações de violência.

Da análise com as 600 usuárias, somente cinco se autodeclararam com vivências lésbicas e bissexuais, sendo duas em Cajazeiras, uma (1) em João Pessoa e duas em Campina Grande. Dessas, três passaram por violência de gênero, sendo uma (1) nas três cidades indicadas anteriormente. É bastante emblemático esse dado, se considerarmos a vulnerabilidade a que estão submetidas as pessoas que destoam da heteronorma, resultando em situações de violência oriundas da homofobia. Mesmo levando em consideração o número reduzido de mulheres que se declararam com vivências homoafetivas no universo da pesquisa, quando analisada a amostragem com o recorte de violência de gênero ficou demarcada a forte marca da violência nestas mulheres.

Apesar de se termos encontrado percentuais elevados de mulheres violentadas alfabetizadas ( $92 \% \mathrm{em}$ Patos, 89,7\% em Campina Grande, 87,5\% em Cajazeiras, 83,9\% em João Pessoa), prevaleceu a não conclusão do ciclo da Educação Básica com os seguintes percentuais: 78,1\% em Patos, 73\% em Campina Grande, 71,4 em Cajazeiras e 65,9 em João Pessoa.

Quanto à inserção no mercado de trabalho, seja na formalidade ou informalidade, destacamos os seguintes achados: em Patos, a maioria (80\%) das usuárias que passaram por processo de violência doméstica e familiar não exerciam atividades remuneradas; em João Pessoa e Campina Grande, um pouco mais da metade da amostra, 57\% e 51,7, respectivamente, também se encontrava nesta condição, sem desempenhar atividades que agregassem valor financeiro. Inversamente a essas três cidades, Cajazeiras apresentou maior percentual $(53,1 \%)$ para a situação de mulheres que desempenhavam trabalho remunerado. Cabe destacar que, excetuando-se Cajazeiras, os percentuais que indicaram a não inserção no mercado de trabalho estiveram acima da metade da amostra.

Refletindo acerca da inclusão no mercado formal de trabalho, foram verificadas variações entre as cidades pesquisadas. A capital do estado apresentou um percentual significativo de $54,2 \%$ de mulheres violentadas que possuíam carteira de trabalho assinada. Em contrapartida, nenhuma das $20 \%$ que exerciam atividades remuneradas em Patos possuíam vínculo formal. Campina Grande e Cajazeiras demarcaram percentuais reduzidos, $21,4 \%$ e $11,8 \%$, respectivamente, de mulheres com vínculos formais de trabalho.

Quanto à renda familiar, a situação majoritária foi de famílias conviverem com até dois salários mínimos (Cajazeiras, 56,3\%; Campina Grande, 65,5\%; João Pessoa, 35,7\%) e de famílias que sobreviviam com até um salário mínimo (Patos, 48\%). Na época da pesquisa, o salário mínimo era de R\$724,00. Percebemos, assim, que a maioria das mulheres violentadas pertenciam a famílias com pequeno poder aquisitivo.

\section{Aspectos da violência doméstica e familiar}

As violências sofridas pelas usuárias das USF foram majoritariamente perpetradas pelos parceiros e ex-parceiros, contabilizando os seguintes percentuais: Cajazeiras, 91\%; Patos, 76\%; Campina Grande, 83\%; e João Pessoa, $94 \%$. As violências praticadas envolveram, com maior frequência, a física e a psicológica, conforme demonstrado na Tabela 3. 
Tabela 3 - Tipos de violência praticadas

\begin{tabular}{l|c|c|c|c}
\hline \multicolumn{1}{c|}{ Tipos de Violência } & Física & Psicológica & Sexual & Patrimonial \\
\hline Cajazeiras & $84 \%$ & $53 \%$ & $06 \%$ & $06 \%$ \\
Patos & $68 \%$ & $56 \%$ & $12 \%$ & $04 \%$ \\
Campina Grande & $93 \%$ & $48 \%$ & $10 \%$ & $20 \%$ \\
\hline João Pessoa & $66 \%$ & $71 \%$ & $20 \%$ & $05 \%$ \\
\hline
\end{tabular}

Fonte: Dados de pesquisa realizada entre julho a dezembro de 2014.

No que diz respeito à procura de ajuda durante o ciclo da violência, ficou patente que mais da metade dessas mulheres optaram por se manter isoladas ou não tiveram condições de deflagrar um processo para coibir a violência a que estavam submetidas. Conforme captado na análise dos dados, somente $43,8 \%$ em Cajazeiras, 28,0\% em Patos, 34,5\% em Campina Grande e 44,6\% em João Pessoa recorreram a alguma ajuda para sair do ciclo da violência.

Vencer o ciclo de violência em que se encontram as mulheres em tal situação depende muito da efetividade da Rede de Atendimento às Mulheres em Situação de Violência, prevista na Lei Maria da Penha, incluindo a qualidade e disponibilidade dos serviços vinculados a essa rede.

Essa Rede de Atendimento se refere ao conjunto de ações e serviços de diferentes setores (em especial, da assistência social, da justiça, da segurança pública e da saúde) que visam "à ampliação e à melhoria da qualidade do atendimento, à identificação e ao encaminhamento adequados das mulheres em situação de violência e à integralidade e à humanização do atendimento" (SILVA et al., 2011, p. 14).

A rede de atendimento deve garantir o acompanhamento às vítimas e empenhar um papel importante na prevenção da violência contra a mulher. Além de ser assistida pelo sistema de justiça criminal, a mulher deve conseguir ter acesso à rede também por meio do sistema de saúde, já que em muitos casos as mulheres passam várias vezes por esse sistema antes de chegarem a uma delegacia ou a um juizado (CERQUEIRA et al., 2018, p. 48).

A Rede de Atendimento às Mulheres em Situação de Violência engloba serviços especializados e não especializados. Compreende os serviços especializados: Casas-abrigo, Delegacias Especializadas de Atendimento às Mulheres (DEAM), Centros de Referência da Mulher, Defensorias da Mulher, Promotorias da Mulher ou núcleos de gênero nos Ministérios Públicos, Juizados Especializados de Violência Doméstica e Familiar Contra a Mulher, Central de Atendimento à Mulher (Ligue 180), Centros Especializados de Assistência Social (CREAS), serviços de saúde voltados para o atendimento aos casos de violência sexual e doméstica, Posto de Atendimento Humanizado nos aeroportos e Núcleo de Atendimento à Mulher nos serviços de apoio ao migrante. Os serviços não especializados incluem hospitais gerais, serviços de atenção básica do SUS, escolas, creches, delegacias comuns, polícia militar, Centros de Referência de Assistência Social (CRAS), ministério público, defensorias públicas (SILVA et al., 2011).

Dos municípios pesquisados, João Pessoa e Campina Grande foram os que mais possuíam serviços especializados para atendimento às mulheres vítimas de violência. Ambas as cidades contavam com os seguintes serviços: Secretarias de Políticas Públicas para as Mulheres; Delegacia Especializada de Atendimento à Mulher; Centro de Referência da Mulher; Casa Abrigo; Juizado de Violência Doméstica e Familiar contra a Mulher; Centros de Referência Especializados de Assistência Social (CREAS), Núcleo da Mulher do Ministério Público; Defensoria Pública Núcleo Mulher; hospitais públicos para atendimento dos casos de violência sexual (João Pessoa contava com três serviços: Maternidade Frei Damião, Instituto Cândida Vargas e o Hospital Arlinda Marques; Campina Grande apenas dispunha do Instituto de Saúde Elpídio de Almeida) (FERREIRA et al., 2015).

Nas cidades de Patos e Cajazeiras, a Rede de Atendimento encontrava-se em processo de desenvolvimento, contando com os seguintes serviços: Secretaria de Políticas para as Mulheres; Delegacia Especializada de 
Atendimento à Mulher; Centro de Referência de Atendimento à Mulher (CRAM); Centro de Referência Especializado de Assistência Social (CREAS); e Serviço de Referência em Casos de Violência Sexual (em Patos, a Maternidade Peregrino Filho, e em Cajazeiras, o Hospital Regional). As duas cidades não possuíam Casa Abrigo, sendo uma das falhas do sistema, pois quando necessitava de abrigo a mulher vítima de violência doméstica precisava ser encaminhada para Campina Grande/PB ou João Pessoa/PB.

Das mulheres usuárias da USF que procuraram apoio durante a situação de violência, a Delegacia Especializada da Mulher foi o serviço mais procurado nas quatro cidades (Cajazeiras 36\%; Patos 29\%; Campina Grande 50\%; João Pessoa 40\%) e nenhuma delas se dirigiu aos Centros de Referência da Mulher, apesar de tal serviço existir nos municípios. Somente em Patos foi registrada a procura pelo Centro de Referência de Assistência Social (CRAS) por 14\% das usuárias violentadas.

A interlocução das usuárias com as USF durante os períodos de agudizamento do ciclo da violência foi bastante inexpressiva, chegando mesmo a inexistir no município de Patos. Em Cajazeiras e João Pessoa apenas $7 \%$ e $8 \%$, respectivamente, procuraram apoio junto à equipe das USF para os devidos encaminhamentos. Campina Grande apresentou diferencial neste contexto, demarcando uma procura de $30 \%$ das usuárias violentadas aos serviços das unidades básicas, buscando direcionamento para sair do ciclo da violência. Cabe destacar que Campina Grande foi uma das cidades pioneiras, em nível de Brasil, na implantação do Programa de Saúde da Família dentro da atenção básica do SUS, em 1994, incorporando na constituição da equipe mínima os profissionais de Serviço Social, os quais estabeleceram vínculo mais direto com a população adscrita, juntamente com os/as Agentes Comunitários de Saúde (ACS). Provavelmente, esse diferencial na formação da equipe mínima e a exitosa experiência na implantação do Programa Saúde da Família justifiquem a maior demanda das usuárias violentadas na procura pelas USF (A PERSISTÊNCIA..., 2004).

\section{Atendimento prestados pelas Unidades de Saúde da Família (USF)}

Para analisar o atendimento prestado pelas USF voltado para as questões de violência familiar e doméstica entre as usuárias, elencamos três abordagens que foram tratadas com as/os enfermeiras/os das USF e as gestoras responsáveis pela pasta de Saúde da Mulher ou sua correlata, quais sejam: o conhecimento acerca dos serviços prestados pela Rede de Atendimento à Mulher Vítima de Violência; o atendimento de usuárias violentadas com os respectivos encaminhamentos; o preenchimento da ficha de notificação compulsória.

No município de Patos, foi unânime o conhecimento das enfermeiras das USF acerca da existência de violência de gênero nas comunidades, porém somente uma referenciou um único caso que chegou à USF, o qual foi encaminhado ao Núcleo de Apoio à Saúde da Família (NASF). Associaram a falta de procura de apoio ao medo e vergonha das usuárias em retratarem a violência, bem como destacaram o receio das ACS e da própria equipe em se envolver com as questões de violência de gênero por medo de represálias dos agressores. Essas enfermeiras desconheciam a ficha de notificação compulsória e a gerente de Atenção Básica destacou que, das 40 USF do município, apenas duas unidades registravam essas fichas de notificação.

Quanto ao conhecimento dos serviços vinculados à Rede de Atendimento, somente a gerente de Atenção Básica tinha informação consistente sobre as instituições vinculadas à referida rede. Duas enfermeiras desconheciam esses serviços e duas outras apenas sabiam da existência da Delegacia da Mulher.

Em relação aos possíveis encaminhamentos dos casos de violência de gênero, apenas uma enfermeira indicou que encaminharia para o serviço de Psicologia e de Serviço Social da policlínica Frei Damião, que é o serviço de média complexidade do município, e outra informou que encaminhou o caso atendido ao serviço de Psicologia do NASF, conforme já mencionado anteriormente.

Das/os quatro enfermeiras/os das USF de Cajazeiras, uma conhecia todos os serviços da Rede de Atendimento, demonstrando domínio e visão crítica acerca dos procedimentos a serem tomados para encaminhar os casos de violência de gênero. Duas/dois enfermeiras/os conheciam parcialmente esses serviços e somente uma (1) soube referenciar o Conselho da Mulher. Note-se que o Conselho da Mulher não possui a função de encaminhar e atuar sobre os casos de violência. A gerente de Saúde da Mulher da Criança e do Adolescente desconhecia os serviços da citada rede.

Três enfermeiras das USF de Cajazeiras reconheceram a existência de violência de gênero entre as usuárias do serviço, informando já terem atendido alguns casos. Deixaram evidente que as usuárias não 
procuravam os serviços das USF como apoio para soluções das vivências de violências. Na grande maioria das vezes, as profissionais percebiam as marcas da violência nos corpos das mulheres, mas não podiam preencher a ficha de notificação, nem encaminhar para os serviços da rede, em função de as usuárias não assumirem a ocorrência da violência. Houve até caso de estupro que não pôde ser encaminhado, nem notificado, em função da negativa da usuária. Somente o enfermeiro informou não ter atendido casos de evidências de violência. Todas/os enfermeiras/os tinham conhecimento da ficha de notificação compulsória, mas só preenchiam com o consentimento das usuárias.

Em João Pessoa, a gestora de Saúde da Mulher informou sobre a articulação da Secretaria de Saúde com Organizações Não Governamentais (ONGs) feministas, tanto para processo de capacitação junto às equipes de saúde como para encaminhamentos voltados à problemática da violência de gênero. A citada gestora mencionou também a parceria com a Secretaria de Políticas para as Mulheres, de âmbito municipal, para realização de algumas ações, especialmente para divulgação dos serviços da Rede de Atendimento. Foi perceptível, durante nossas visitas às USF, a exposição de cartazes informativos dos serviços de atendimento à violência doméstica e familiar fixados nos murais das unidades. A referida gestora informou que após o trabalho de divulgação desses serviços houve aumento da procura de usuárias com situações de violência nas USF e maior número de notificações. Tal situação foi confirmada pelas enfermeiras das USF que, por unanimidade, confirmaram ter atendido casos de mulheres violentadas. Apesar de a grande maioria dos casos terem sido percebidos pelas profissionais ou terem recebido a informação a partir dos/as ACS e/ou familiares, sem a fala explícita da usuária acerca da violência, houve um processo de conversa e convencimento das enfermeiras com as mulheres violentadas para procurarem os serviços vinculados à Rede de Atendimento, tendo sido feitos encaminhamentos para a Delegacia da Mulher, ONGs e hospitais. Todas as enfermeiras das USF e a gestora de Saúde da Mulher de João Pessoa possuíam domínio acerca dos serviços da Rede de Atendimento.

Das cinco enfermeiras entrevistadas, somente uma não tinha conhecimento da ficha de notificação da violência. As demais confirmaram o preenchimento das fichas, mesmo as usuárias tendo se negado a dar encaminhamento ao processo de denúncia. Essa postura foi diferenciada das/os enfermeiros de Cajazeiras, que somente preenchiam as fichas de notificação quando as usuárias confirmavam a vivência da violência e se predispunham a denunciar.

A coordenadora de Saúde da Mulher de Campina Grande não tinha familiaridade com as questões relacionadas aos temas da violência de gênero, não conhecendo a demanda de recebimento pelo setor de vigilância epidemiológica das fichas de notificação compulsória, nem conhecia, em sua amplitude, a Rede de Atendimento. Das quatro enfermeiras entrevistadas, apenas uma relatou ter recebido mulheres violentadas, na maioria das vezes, não tendo sido relatado pelas usuárias a violência, tendo a profissional percebido as marcas no corpo. As demais informaram ter conhecimento de casos de violência em usuárias informados pelos/as ACS e assistente social da equipe, durante as reuniões do serviço, sem, contudo, se envolver com a problemática. Ficou evidente a falta de envolvimento dessas três enfermeiras com as questões relacionadas à violência de gênero entre as usuárias das USF. Inclusive, as entrevistadas ainda informaram desconhecer os procedimentos para os devidos encaminhamentos dos casos de violência, debitando aos profissionais de Serviço Social e ACS as responsabilidades para os atendimentos desses casos.

Sem destoar das narrativas desenvolvidas no contexto das entrevistas, três enfermeiras das USF de Campina Grande desconheciam os serviços da Rede de Atendimento e apenas uma informou que conhecia a Delegacia da Mulher e o Centro de Referência de Atendimento à Mulher. Com relação à ficha de notificação compulsória, somente a enfermeira que identificou casos de violência durante seus atendimentos informou que conhecia a ficha e notificava; uma enfermeira conhecia a ficha, mas nunca a utilizou e as duas demais entrevistadas desconheciam totalmente essa ficha.

\section{Considerações finais}

O fenômeno da violência contra a mulher precisa ser analisado em uma perspectiva ampla, a fim de desvendar os fatores potencializadores e obstaculizadores para o seu enfrentamento. A violência doméstica e familiar não pode ser dissociada da desigualdade social e estrutural às quais está submetida boa parte das 
mulheres em situação de violência, caracterizada pelo não acesso aos direitos sociais, desemprego, miséria, racismo, misoginia, entre outras expressões da questão social.

Sem buscar homogeneização dos resultados, mas seguindo a regra das análises estatísticas, apontamos, nestas considerações finais, os indicadores prevalecentes dos marcadores sociais das usuárias das USF que passaram por processo de violência doméstica e familiar, nas quatro cidades. Majoritariamente, encontravamse em condições econômicas precárias com pequeno poder aquisitivo; estavam em idade reprodutiva; se autoidentificaram, em sua maioria, como cisgêneras e afrodescendentes (negras, pardas e morenas); viviam relacionamentos estáveis heteronormativos; indicaram vivenciar experiências heteroafetivas; não chegaram a concluir o Ensino Médio; acima da metade das mulheres não realizavam atividades remuneradas, excetuandose a cidade de Cajazeiras.

Os aspectos relacionados à violência de gênero demarcaram maior incidência na cidade de João Pessoa, confirmando a marca que esse município registrava, em 2015, no ranque nacional das capitais brasileiras, com maiores índices de violência contra a mulher. Predominou a ocorrência de dois tipos de violências, a física e a psicológica, as quais na grande maioria ocorriam em uma mesma situação. A violência sexual também foi identificada, com menor incidência.

Apesar de ter ocorrido a implantação da Rede de Atendimento às Mulheres em Situação de Violência nos municípios de João Pessoa e Campina Grande, bem como já terem sido instalados Centros de Referência da Mulher nas quatro cidades pesquisadas, ficou evidenciada a falta de acesso das mulheres violentadas a essa rede, quando detectado que mais da metade dessas mulheres não acessaram qualquer serviço da citada rede. As que procuraram apoio institucional o fizeram, majoritariamente, via Delegacias Especializadas de Atendimento às Mulheres, não se tendo registro de buscarem os Centros de Referências da Mulher.

As Unidades Saúde da Família, serviços aos quais as usuárias mantinham ou deveriam manter acesso constante, devido à própria dinâmica do atendimento previsto no modelo da atenção básica do SUS, esteve longe de ser canal de interlocução das mulheres violentadas com os serviços especializados voltados às mulheres em situação de violência. A prerrogativa de referenciamento, subjacente aos serviços de atenção básica, para os casos de violência de gênero, pouco se fez presente nas dinâmicas de atendimento das enfermeiras, excetuando-se a cidade de João Pessoa que possuía uma política de capacitação das equipes articulada com o movimento feminista e a Secretaria de Política Públicas para as Mulheres.

Cabe demarcar que Campina Grande apresentou diferencial em relação aos demais municípios, no que diz respeito à procura de apoio das mulheres violentadas junto às USF, registrando incidência de $30 \%$. Esse diferencial pode ser explicado pelo histórico de inserção de assistentes sociais na equipe mínima do Programa Saúde da Família nesse município, desde sua criação.

\section{Referências}

A PERSISTÊNCIA da memória: 10 anos do Programa Saúde da Família de Campina Grande. Jornal do PSF, Campina Grande: Mídia Assessoria de Comunicação Ltda., 2004.

BRASIL. Lei n ${ }^{\circ} 10.778$, de 24 de novembro de 2003. Estabelece a notificação compulsória, no território nacional, do caso de violência contra a mulher que for atendida em serviços de saúde públicos ou privados. Brasília, DF: Presidência da República, 2003. Disponível em: http://www.planalto.gov.br/ccivil_03/leis/2003/110.778.htm. Acesso em: 9 set. 2020.

BRASIL. Lei $\mathrm{n}^{\circ} 11.340$, de 7 de agosto de 2006. Cria mecanismos para coibir a violência doméstica e familiar contra a mulher, nos termos do $\S 8^{\circ}$ do art. 226 da Constituição Federal, da Convenção sobre a Eliminação de Todas as Formas de Discriminação contra as Mulheres e da Convenção Interamericana para Prevenir, Punir e Erradicar a Violência contra a Mulher; dispõe sobre a criação dos Juizados de Violência Doméstica e Familiar contra a Mulher; altera o Código de Processo Penal, o Código Penal e a Lei de Execução Penal; e dá outras providências. Brasília, DF: Presidência da República, 2006. Disponível em: http://www2.senado.leg.br/bdsf/handle/ id/566467. Acesso em: 9 set. 2020

BRASIL. Lei $\mathrm{n}^{\circ} 12.845$, de $1^{\circ}$ de agosto de 2013. Dispõe sobre o atendimento obrigatório e integral de pessoas em situação de violência sexual. Brasília, DF: Presidência da República, 2013. Disponível em: http://www.planalto.gov.br/ccivil_03/_ato2011-2014/2013/lei/ 112845.htm. Acesso em: 9 set. 2020.

BRASIL. Lei no 13.104, de 9 de março de 2015. Altera o art. 121 do Decreto-Lei nº 2.848, de 7 de dezembro de 1940 - Código Penal, para prever o feminicídio como circunstância qualificadora do crime de homicídio, e o art. $1^{\text { }}$ da Lei n n $^{\circ} .072$, de 25 de julho de 1990 , 
para incluir o feminicídio no rol dos crimes hediondos. Brasília, 2015. Disponível em: http://www.planalto.gov.br/ccivil_03/_ato20152018/2015/lei/113104.htm\#: :text=Altera\%20 o\%20art.no\%20rol\%20dos\%20crimes\%20hediondos. Acesso em: 15 dez. 2020.

BRASIL. Ministério da Saúde. Portaria no 2.359, de 15 de outubro de 2012. Aprova Etapa I do Plano de Ação da Rede Cegonha do Estado da Paraíba e aloca recursos financeiros para sua implementação. Brasília, DF: Gabinete do Ministro, 2012. Disponível em: http://bvsms.saude.gov.br/bvs/saudelegis/gm/2012/prt2359_15_10_2012.html. Acesso em: 9 set. 2020.

CERQUEIRA, D. et al. Atlas da violência 2018. Rio de Janeiro: IPEA/SPFB, 2018. Disponível em: https://www.ipea.gov.br/portal/ index.php?option=com_content\&view=article \&id=33410\&Itemid=432. Acesso em: 15 ago. 2020.

FECHINE, D. Feminicídios são mais de 50\% dos assassinatos de mulheres no primeiro semestre de 2019. G1 PB, jul. 2019. Disponível em: https://g1.globo.com/pb/paraiba/noticia/2019/07/21/feminicidios-sao-mais-de-50percent-dos-assassinatos-de-mulheres-no-1osemestre-de-2019-na-pb.ghtml. Acesso em: 03 ago. 2019.

BRASIL. Política Nacional de Atenção Integral à Saúde da Mulher: princípios e diretrizes. Brasília: Ministério da Saúde, 2004.

FERREIRA, A. M. P. et al. Mulheres em situação de violência: olhares feministas sobre a rede de atendimento. João Pessoa: Ideia, 2015. GUSTAFSON, J. Brasil caminha para liderar o ranking mundial de violência contra a mulher. Portal Catarinas, jan. 2019. Disponível em: https://catarinas.info/brasil-caminha-para-liderar-ranking-mundial-da-violencia-contra-mulher/. Acesso em: 03 ago. 2020.

MAPA da Violência 2015: Homicídio de Mulheres no Brasil. FLACSO BRASIL, Brasília, 9 nov. 2015. Disponível em: http://flacso. org.br/?p=13485. Acesso em: 14 set. 2019.

OSÓRIO, R. G. O sistema de classificação de "cor ou raça” do IBGE. Textos para discussão, Rio de Janeiro/RJ, n. 996, nov. 2003. Disponível em: http://www.ibge.gov.br/confest_e_confege/pesquisa_trabalhos/arquivosPDF/M255_02.pdf. Acesso em: 3 set. 2019.

PB registra 46 assassinatos de mulheres no $1^{\circ}$ semestre de 2020. Portal Correio, ago. 2020. Disponível em: https://portalcorreio.com. br/pb-registra-46-assassinatos-de-mulheres-no-primeiro-semestre-de-2020. Acesso em: 09 set. 2020.

SILVA, T. S. et al. Rede de Enfrentamento à Violência contra as Mulheres. Secretaria de Políticas para as Mulheres, Presidência da República: Brasília, 2011. Disponível em: https://www12.senado.leg.br/institucional/omv/entenda-a-violencia/pdfs/rede-deenfrentamento-a-violencia-contra-as-mulheres. Acesso em 15 set. 2020.

\section{Notas}

1 De acordo com o art. $5^{\circ}$ da Lei Maria da Penha, violência doméstica e familiar contra a mulher é "qualquer ação ou omissão baseada no gênero que lhe cause morte, lesão, sofrimento físico, sexual ou psicológico e dano moral ou patrimonial" (BRASIL, 2006, p. 19).

2 Informações obtidas pelo site: http://tabnet.datasus.gov.br/cgi/deftohtm.exe?siab/cnv/SIABSPB.def. Acesso em: 19 maio 2014.

3 Cabe destacar que a amostra das/os enfermeiras/os foi constituída majoritariamente por pessoas do gênero feminino, tendo-se somente entrevistado um enfermeiro (gênero masculino) na cidade de Cajazeiras. Acrescente-se, também, que todas as gestoras eram do gênero feminino.

4 Mulheres violentadas em idade reprodutiva: Cajazeiras (53,2\%); Patos (48,0\%); Campina Grande (41,3\%); João Pessoa (48,2\%).

\section{Idalina Maria Freitas Lima Santiago}

imfls@uol.com.br

Doutora em Ciências Sociais pela Pontifícia Universidade Católica de São Paulo (PUC/SP)

Professora do Programa de Pós-Graduação em Serviço Social da Universidade Estadual da Paraíba (UEPB)

\section{UEPB}

Rua Domitila Cabral de Castro, s/n, Central de Aulas, sala 234, Bodocongó

Campina Grande - Paraíba - Brasil

CEP: 58.429-570

\section{Agradecimentos}

Agradecimentos à equipe de pesquisadores/as que participou do processo investigativo (coordenado pela autora do presente artigo), às mulheres usuárias das Unidades de Saúde da Família do SUS, às enfermeiras das referidas Unidades e gestoras das áreas de Saúde da Mulher e de Atenção Básica dos municípios de Patos, Cajazeiras, Campina Grande e João Pessoa no estado da Paraíba.

Agência financiadora

Pesquisa financiada pelo Conselho Nacional de 
Desenvolvimento Científico e Tecnológico, Edital MCTI/ CNPq/SPM-PR/MDA N ${ }^{\circ} 32 / 2012$. Processo institucional $n^{\circ}$ 405265/2012-3, vigência 17/12/2012 a 16/06/2015.

\section{Contribuicões das autoras}

As análises e escrita do texto foram elaboradas pela autora do presente artigo, tendo por referência a base de dados empíricos coletadas durante o processo investigativo que contou com a participação de pesquisadores/as financiados/as pelo edital MCTI/CNPq/SPM-PR/MDA no 32/2012 e pelo Programa Institucional de Bolsas de Iniciação Científica/CNPq: Ednaldo da Costa Braz (DTI-C/CNPq), Josilene Maria de Oliveira (DTI-C/CNPq), Maria Danielle Cristina Morais Sousa (ITI-A/ CNPq), Rafaella dos Santos Porfírio (ITI-A/CNPq), Maria Luiza Pereira Leite (ITI-A/CNPq), Cleonice Evellyn Oliveira
Lima (DTI-C/CNPq), Josilene Barbosa do Nascimento (PNPD/ CAPES/PPGSS), Janaíra de Sousa Ferreira (PIBIC/CNPq), Lissandra Monteiro Herculano (PIBIC/CNPq), Nataly Barros Pereira (PIBIC/CNPq) e Damião Flávio dos Santos.

Aprovação por Comitê de Ética e consentimento para participação

O projeto de pesquisa foi aprovado pelo Comitê de Ética com o protocolo $\mathrm{n}^{\circ} 33787114.0 .0000 .5187$ e todas/os participantes assinaram o Termo de Consentimento Livre e Esclarecido.

Consentimento para publicação

Consentimento da autora para publicação.

Conflito de interesses

Não há conflito de interesses. 